\title{
Outcomes after repair or replacement of dysfunctional quadricuspid aortic valve
}

\author{
J. Jay Idrees, MD, Eric E. Roselli, MD, Amr Arafat, MD, Douglas R. Johnston, MD, Lars G. Svensson, MD, \\ $\mathrm{PhD}$, Joseph F. Sabik III, MD, and Gosta B. Pettersson, MD, PhD
}

Objective: Quadricuspid aortic valve (QAV) morphology is rare $(0.008 \%)$ but often dysfunctional, manifesting early or late in life. No large series have been evaluated. Current objectives are to characterize these patients, and assess repair possibilities and outcomes.

Methods: From 1989 to 2010, a total of 19,722 patients underwent aortic valve surgery at Cleveland Clinic. Thirty-one $(0.0016 \%)$ patients had dysfunctional QAV and underwent repair or replacement for moderate to severe aortic regurgitation $(n=21)$, stenosis $(n=5)$, or both $(n=4)$. One additional patient with functional QAV required excision of fibroelastoma. The mean age was $58 \pm 18$ years. Ascending aortic diameter was $\geq 4 \mathrm{~cm}$ in $13(42 \%)$ patients, and 7 required ascending repair (mean diameter: $4.8 \pm 0.4 \mathrm{~cm}$ ). Three patients had anomalous origin of coronary artery, and 1 required repair.

Results: The aortic valve was repaired in $7(23 \%)$ patients and replaced in $23(73 \%)$. The decision of which procedure to use was based on intraoperative findings. The Ross procedure was performed in 1 patient who had endocarditis. Most patients in the repair group had leaflet prolapse that was repaired with accessory cusp excision and commisuroplasty. The mean gradient after repair was $14 \pm 5 \mathrm{~mm} \mathrm{Hg}$. Bioprostheses were used in all replacements; median valve size was $25 \mathrm{~mm}$ (range: $21-27 \mathrm{~mm}$ ). No operative mortality occurred. One patient suffered nonpermanent stroke after aortic valve replacement. There was no myocardial infarction, renal failure, respiratory failure, or reoperation for bleeding. The median follow-up time was 38 months; 1 patient required replacement 13 years after previous repair for recurrent regurgitation and stenosis.

Conclusions: Quadricuspid aortic valve dysfunction includes both regurgitation and stenosis; repair may be feasible in some patients with regurgitation, but most require replacement. Aortic root and ascending dilatation are frequent, and further studies are needed. (J Thorac Cardiovasc Surg 2015;150:79-82)

See related commentary on pages $82-3$.

Quadricuspid aortic valve (QAV) morphology is rare. Autopsy studies have reported an incidence of $0.003 \%$ to $0.008 \%{ }^{1}$ Owing to improvements in techniques and more access to diagnostic imaging, this pathology is now being increasingly recognized.

Most cases are diagnosed incidentally, but some present with complications, including aortic regurgitation and stenosis, and require intervention. Prior studies have described QAV morphology and natural history, but only a few have reported outcomes after aortic valve repair or replacement in these patients. ${ }^{1-9}$ The association of the bicuspid aortic

From the Department of Thoracic and Cardiovascular Surgery, Heart and Vascular Institute, Cleveland Clinic, Cleveland, Ohio.

Read at The American Association for Thoracic Surgery Florida Valve International, Miami, Florida, March 7-9, 2014.

Received for publication March 3, 2014; revisions received Feb 19, 2015; accepted for publication March 15, 2015; available ahead of print April 18, 2015.

Address for reprints: Eric E. Roselli, MD, Department of Thoracic and Cardiovascu-

lar Surgery, Cleveland Clinic, 9500 Euclid Ave/Desk J4-1, Cleveland, OH 44195-

5108 (E-mail: roselle@ccf.org).

$0022-5223 / \$ 36.00$

Copyright (c) 2015 by The American Association for Thoracic Surgery

http://dx.doi.org/10.1016/j.jtcvs.2015.03.019 valve to QAV morphology is well known; by contrast, the association between ascending aneurysm and QAV morphology is less so. ${ }^{1-4}$ The objectives of this study are to characterize patients with dysfunctional QAV and assess repair possibilities and outcomes.

\section{METHODS \\ Patients}

From 1989 to 2010 , a total of 19,722 patients underwent aortic valve surgery at the Cleveland Clinic. Thirty-one patients $(0.0016 \%)$ were identified who had a quadricuspid aortic valve. Indications for these 31 patients included moderate to severe aortic regurgitation $(n=21 ; 68 \%)$, aortic stenosis $(n=5$; $16 \%)$ or both $(n=4 ; 13 \%)$. One patient had a normally functioning QAV and presented with fibroelastoma lesions on the cusps. The mean ejection fraction was $50 \% \pm 11 \%$. In patients with regurgitation, the mean end diastolic left ventricular size was $5.5 \pm 1 \mathrm{~cm}$. The mean age was $58 \pm 18$ years.

The ascending aortic diameter was $\geq 4 \mathrm{~cm}$ in $13(42 \%)$ patients; of these, 7 required ascending aortic repair. The mean ascending aortic diameter in patients who underwent ascending repair was $4.8 \pm 0.4 \mathrm{~cm}$. An anomalous origin of a coronary artery was discovered in $3(10 \%)$ patients In 2 patients, the coronaries were partially obstructed by the commissure of the fourth cusp, but this issue was addressed by valve repair. In the third patient, the left main coronary artery arose from the noncoronary sinus and was reimplanted as a button in the native position during root replacement. The study was approved by the institutional review board at the Cleveland Clinic, and the requirement for patient consent was waived. Preoperative patient characteristics are summarized in Table 1. 


\section{Abbreviation and Acronym}

$\mathrm{QAV}=$ quadricuspid aortic valve

\section{Repair Methods}

Of the 31 patients, the aortic valve was repaired in $7(23 \%)$, but 23 $(73 \%)$ underwent aortic valve replacement, including 1 patient with endocarditis, in whom a Ross procedure was performed. Another patient had fibroelastoma of the valve cusps and was treated with surgical excision of the lesions, but did not undergo valve repair or replacement, because the QAV was functioning well.

Fifteen patients required 24 additional concomitant procedures to treat cardiac comorbidities. These included: ascending aortic replacement $(n=7)$, coronary bypass grafting $(n=10)$, mitral valve repair $(n=4)$, maze procedure $(n=1)$, and repair of anomalous coronary origin $(n=1)$. In addition, the latter patient had root aneurysm, and the coronaries were reimplanted on the surgical graft as part of the root replacement procedure.

\section{Surgical Techniques}

Aortic valve repair. All 7 patients in this group had moderate to severe aortic regurgitation at presentation; 1 had aortic stenosis in addition. The choice of repair technique was guided by the intraoperative findings and surgeon preference. Two types of QAV morphologies were noted on intraoperative inspection. Patients had either 4 distinct cusps, with the additional leaflet being the accessory "4th cusp" that was the smallest in size ( $n=4$ of 7 ), or 3 cusps, including 1 conjoint cusp with a raphe (as seen in patients with a bicuspid aortic valve) forming a larger cusp that was often prolapsing ( $n=3$ of 7 ) (Figure 1). In a few cases, 2 of the 4 cusps were normal in size, but the other 2 were small, with a fused or incomplete commissure. This situation resulted in improper coaptation of cusps, resulting in regurgitation, as described by Jeanmart and colleagues. ${ }^{10}$

Those who had 4 distinct cusps underwent "tricuspidization," with excision of the accessory cusp $(n=4)$. Of the remaining 3 patients who had a prolapsing conjoint cusp, 2 underwent repair with triangular resection. The other had a conjoint left and right coronary cusp and 2 small leaflets in place of the noncoronary cusp. This patient underwent "bicuspidization" by plication of the raphe between the left and right coronary cusps and closure of the commisure between the 2 noncoronary cusps (Figure 1). In all cases, a commisuroplasty was performed with subcommisural and/or supracommisural sutures. ${ }^{11}$

Aortic valve replacement. Most patients in this series underwent aortic valve replacement $(\mathrm{n}=23 ; 73 \%)$, and the most common indication was aortic regurgitation $(n=15)$. A few presented with aortic stenosis $(\mathrm{n}=5)$ and 3 had both. On intraoperative inspection, patients with stenosis had thickened, fibrosed, and calcified leaflets, with or without fusion, whereas the mechanism of aortic insufficiency was poor coaptation and degeneration of the leaflets. One patient had endocarditis. The surgical approach was via sternotomy in all patients, and 3 were done as a mini incision. Bioprostheses were used in all patients, and the median valve size was $25 \mathrm{~mm}$ (range: $21-27 \mathrm{~mm}$ ).

\section{Outcomes and Statistics}

Renal failure was defined as a need for hemodialysis; respiratory failure was defined as a need for reintubation or tracheostomy after surgery. Because the total number of events was small, a descriptive analysis was performed. Categoric variables are summarized by frequencies and percentages, and continuous variables are summarized by median or mean \pm standard deviation.

\section{RESULTS}

The mean gradient after repair was $14 \pm 5 \mathrm{~mm} \mathrm{Hg}$. No operative mortality occurred. One patient suffered a nonpermanent stroke after aortic valve replacement. No incidences occurred of myocardial infarction, renal failure, respiratory failure, or reoperation for bleeding. The median follow-up time was 40 months; it was $>5$ years in $31 \%$. Echocardiography-based follow-up evaluation was possible for $26(84 \%)$ of the patients; the median was 3 years. No significant aortic growth was noted during this period.

In the repair group $(n=7), 2$ patients were lost to follow up; the median follow-up time was 7.6 years. One patient presented 13 years after the initial QAV repair, with recurrent regurgitation and stenosis, and was treated with aortic valve replacement. Of the remaining repair patients, 1 patient developed moderate stenosis, and another developed moderate regurgitation, as shown by echocardiography, and these patients were put on a continued surveillance program.

Among those who underwent valve replacement, 2 patients developed moderate stenosis that did not require reoperation as of this writing, and 1 patient suffered endocarditis of the bioprosthesis. This patient underwent re-replacement of the aortic valve, with a $22-\mathrm{mm}$ homograft. The mean follow-up prosthetic valve gradient was $15 \pm 7 \mathrm{~mm} \mathrm{Hg}$.

Overall, 6 late deaths occurred. Two patients died of endstage renal disease; 1 died as a result of complications of liver cirrhosis; and the exact cause of death is unknown for the other 3 patients.

\section{DISCUSSION}

Although patients with dysfunctional quadricuspid aortic valve represent a minority among those with aortic valve disease, this morphology is being increasingly recognized, and recent echocardiography studies have reported an incidence of $0.01 \%$ to $0.04 \%{ }^{3,5}$ The incidence in our population of surgical aortic valve cases was even lower than that described in these studies, suggesting that this anomaly is not always pathologic. This experience demonstrates that QAV dysfunction most commonly presents with regurgitation, but it can present with stenosis and is commonly associated with ascending aneurysm. Aortic valve repair can be attempted in select patients with regurgitation, but most such patients require valve replacement.

The functional status of a quadricuspid aortic valve is related to the morphology of the cusps and the extent of degeneration. Even though these patients have had QAV since birth, the valve did not become dysfunctional and/or produce symptoms until later in life. In the current experience, the mean age at presentation was $58 \pm 18$ years. This finding is consistent with what has been reported in prior studies and suggests that the asymmetry of the QAV cusp size and shape is not severe enough initially to be dysfunctional in most cases, but it may worsen and become symptomatic owing to progressive degeneration. ${ }^{1-3}$ Patients with prolapsing, conjoint larger cusps, and those with smaller cusps resulting in poor coaptation, seem to be particularly prone to degeneration. 
TABLE 1. Patient characteristics and operative details

\begin{tabular}{lc}
\hline \multicolumn{1}{c}{ Characteristic } & Value $(\mathbf{N}=\mathbf{3 1})$ \\
\hline Demographics & \\
Age, mean \pm SD (y) & $58 \pm 18$ \\
Gender, male & $21(68)$ \\
Aortic and aortic valve pathology & \\
Aortic valve & \\
$\quad$ Regurgitation & $21(68)$ \\
$\quad$ Stenosis & $5(16)$ \\
$\quad$ Both & $4(13)$ \\
Root or ascending aortic diameter $>4$ cm & $13(42)$ \\
Diameter in patients with ascending repair, & $4.8 \pm 0.4$ \\
mean \pm SD (cm) & \\
Anomalous origin of coronary arteries & $3(10)$ \\
Surgical treatment & \\
Aortic valve replacement & $23(73)$ \\
$\quad$ Valve size, median (range) (mm) & $25(21-27)$ \\
$\quad$ Bioprosthesis & $23(73)$ \\
$\quad$ Ross procedure & $1(3)$ \\
Aortic valve repair & $7(23)$ \\
$\quad$ Tricuspidization + commisuroplasty & $4(13)$ \\
Triangular resection + commisuroplasty & $3(10)$ \\
Concomitant procedures & \\
Ascending aortic repair & $7(23)$ \\
Coronary artery bypass grafting & $10(32)$ \\
Mitral valve repair & $4(13)$ \\
Maze procedure & $1(3)$ \\
Anomalous origin of coronary artery repair & $1(3)$ \\
\hline Values are given in n (\%), unless otherwise indicated. $S D$, Standard deviation.
\end{tabular}

Contrary to what has been reported in most previous studies, root and ascending aortic aneurysm was a common finding in the current experience. ${ }^{1-9}$ Comprehensive computed tomography-based imaging analysis of preoperative scans using 3-dimensional reconstruction techniques showed that the proximal aortic diameter was $\geq 4 \mathrm{~cm}$ in $13(42 \%)$, and $>4.5 \mathrm{~cm}$ in $7(22 \%)$ patients. The latter group underwent ascending aortic repair. The exact mechanisms of aortic dilatation are unknown in this population, but they may be similar to those in patients with a bicuspid aortic valve. A congenital structural defect and altered hemodynamics related to valve morphology have been postulated to both play a role. ${ }^{1,12,13}$ In addition, the presence of QAV is commonly associated with other congenital cardiac anomalies, such as anomalous origin of coronary arteries. ${ }^{6}$ This fact was noted in $10 \%$ of patients in our series. More studies are needed to further investigate these associations.

Various treatments of dysfunctional QAV have been described. Aortic valve replacement remains the most common, but a few studies have reported success with repair. These techniques involve resection of the dysfunctional QAV cusp, resulting in "tricuspidization" of the aortic valve. An alternative approach involves plication and commissural closure, resulting in "bicuspidization" of the QAV. ${ }^{7,8}$

In this experience, the choice of procedure was based on disease severity, condition of the QAV cusps during intraoperative inspection, and surgeon preference. The aortic valve was replaced when the disease was more advanced and the cusps were severely degenerated, but in a few patients with relatively well preserved cusps, a repair was attempted $(\mathrm{n}=7 ; 23 \%)$. The repair patients all presented with predominantly aortic regurgitation.

The techniques for repair were similar to those described in the literature. . $^{-9}$ A "tricuspidization" after excision of the accessory cusp was the preferred technique in patients with 4 distinct cusps. In those with a conjoint prolapsing
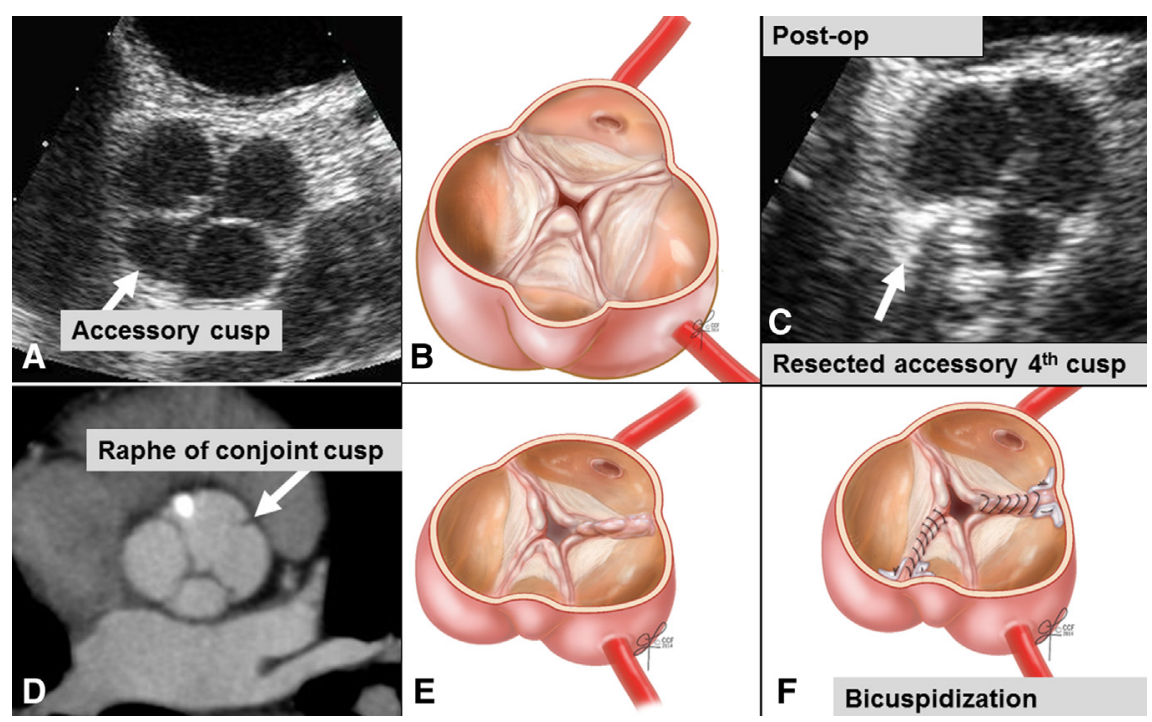

FIGURE 1. Preoperative echocardiogram (A, B) showing quadricuspid aortic valve with 4 distinct cusps and a computed tomography image; and diagram (D, E) showing conjoint cusp. C, Postoperative echocardiogram image after resection of the accessory cusp "tricuspidization." F, Illustration of the bicuspidization technique after commisuroplasty in a patient with a conjoint cusp and 2 small cusps. 
cusp, a triangular resection followed by commisuroplasty was chosen. One patient had a conjoint large cusp, and the remaining 2 cusps were very small, so a plication of the conjoint cusp was performed; the commisure between the remaining cusps was closed, resulting in bicuspidization of the QAV. Misfield and colleagues ${ }^{9}$ described a case using the subcoronary Ross procedure, in 1 patient who had QAV and severe regurgitation. ${ }^{9}$ Although this technique was effective for treating this pathology, $42 \%$ of our patients had some evidence of aortopathy, which can predispose them to late failure.

In summary, QAV dysfunction includes both regurgitation and stenosis. Repair may be feasible in some patients with regurgitation, but most require valve replacement. Aortic root and ascending dilatation is frequent, and further studies of this population may clarify the etiology of congenital aortic valve disease.

\section{Conflict of Interest Statement}

Authors have nothing to disclose with regard to commercial support.

\section{References}

1. Feldman BJ, Khandheria BK, Warnes CA, Seward JB, Taylor CL, Tajik AJ. Incidence, description and functional assessment of isolated quadricuspid aortic valves. Am J Cardiol. 1990;65:937-8.
2. Hurwitz LE, Roberts WC. Quadricuspid semilunar valve. Am J Cardiol. 1973;31: 623-6.

3. Simonds JP. Congenital malformations of the aortic and pulmonary valves. Am J Med Sci. 1923;166:584-95.

4. Svensson LG, Kim KH, Blackstone EH, Rajeswaran J, Gillinov AM, Mihaljevic T, et al. Bicuspid aortic valve surgery with proactive ascending aorta repair. J Thorac Cardiovasc Surg. 2011;142:622-9.

5. Jagannath AD, Johri AM, Liberthson R, Larobina M, Passeri J, Tighe D, et al. Quadricuspid aortic valve: a report of 12 cases and a review of the literature. Echocardiography. 2011;28:1035-40.

6. Tutarel O. Quadricuspid aortic valves and anomalies of the coronary arteries. $J$ Thorac Cardiovasc Surg. 2004;127:897.

7. Schmidt KI, Jeserich M, Aicher D, Schäfers HJ. Tricuspidization of the quadricuspid aortic valve. Ann Thorac Surg. 2008;85:1087-9.

8. Luciani GB, Morjan M, Faggian G, Mazzucco A. Repair of quadricuspid aortic valve by bicuspidization: a novel technique. Interact Cardiovasc Thorac Surg. 2010;11:348-50.

9. Misfeld M, Christiansen F, Sievers HH. Ross procedure in a quadricuspid aortic valve. Ann Thorac Surg. 2005:80:1110-1.

10. Jeanmart H, de Kerchove L, El Bitar F, Glineur D, Vandyck M, Noirhomme P, et al. Tricuspidation of quadricuspid aortic valve: case reports. J Heart Valve Dis. 2007;16:148-50.

11. Svensson LG, Al Kindi AH, Vivacqua A, Pettersson GB, Gillinov AM, Mihaljevic T, et al. Long-term durability of bicuspid aortic valve repair. Ann Thorac Surg. 2014;97:1539-47; discussion 1548.

12. Vismara R, Mangini A, Romagnoni C, Contino M, Redaelli A, Fiore GB, et al. Invitro study of a porcine quadricuspid aortic valve. J Heart Valve Dis. 2014;23: 122-6.

13. Ingham GW. Congenital malformations of the pulmonic and aortic valve. Ann Intern Med. 1938;12:609-13.

Key Words: Quadricuspid, aortic valve, dysfunctional, AVR, repair, replacement, aortopathy, tricuspidization

\title{
EDITORIAL COMMENTARY
}

\section{Quadricuspid aortic valve repair: Pushing the limits!}

\author{
Munir Boodhwani, MD, MMSc, FRCSC
}

See related article on pages $79-82$.

Quadricuspid aortic valve (QAV) is a rare congenital abnormality that often leads to hemodynamically significant

\footnotetext{
From the Division of Cardiac Surgery, University of Ottawa Heart Institute, Ottawa, Ontario, Canada.

Disclosures: Authors have nothing to disclose with regard to commercial support.

Received for publication March 30, 2015; accepted for publication March 30, 2015; available ahead of print May 1, 2015.

Address for reprints: Munir Boodhwani, MD, MMSc, FRCSC, Division of Cardiac Surgery, University of Ottawa Heart Institute, Room H3405, 40 Ruskin St, Ottawa, Ontario, Canada K1Y 4W7 (E-mail: mboodhwani@ottawaheart.ca).

J Thorac Cardiovasc Surg 2015;150:82-3

$0022-5223 / \$ 36.00$

Copyright (c) 2015 by The American Association for Thoracic Surgery http://dx.doi.org/10.1016/j.jtcvs.2015.03.059
}

valvular disease, typically in the fourth, fifth, or sixth decade of life. A number of associated cardiac abnormalities have been described, including proximal aortic dilatation, coronary artery anomalies, and ventricular and atrial septal defects. QAVs can have a variety of different configurations, which were originally classified by Hurwitz and Rob-

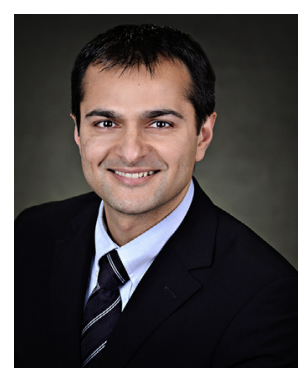
erts $^{1}$ in 1973, largely on the basis of the sizes of the individual cusps. Interestingly, in their study of 11 autopsy specimens, only 5 valves were functionally abnormal, suggesting that many patients with this abnormality may never have development of significant valve disease and are seen for medical attention. Although the most common surgical 